\title{
Parent absenteeism and adolescent work in South Africa: An analysis of the levels and determinants of adolescents who work 10 or more hours a week
}

\author{
Nicole De Wet \\ Demography and Population Studies, University of the Witwatersrand \\ Private Bag 3, University of the Witwatersrand, 2050 \\ Nicole.dewet@wits.ac.za1
}

\begin{abstract}
Using data from the 2010 Survey of Activities of Young People (SAYP) this paper examines the relationship between parent absenteeism and adolescents' (I0-I7 years old) participation in the labour force in South Africa. Due to widespread poverty and the impact of HIV/AIDS, adolescents are forced to forego schooling to seek employment. As Stanton et al. (2004) posited, parent absenteeism affects adolescents' school completion rates and is associated with risky behaviour. This paper argues that parent absenteeism also forces adolescents to seek employment. Descriptive statistics and multivariate logistic regression are used. Results show that 1.58 adolescents per 1,000 adolescent population work 10 or more hours a week. Further, $38.7 \%$ of adolescents have at least one parent absent from the household. Almost $2 \%$ of adolescents who have at least one parent absent are not enrolled in school. Finally, adolescents are less likely to work more than 10 hours a week if a mother is absent from the household (0.34), yet more likely to work more than 10 hours if $a$ father is absent $(I .2 I)$.
\end{abstract}

Keywords: Adolescents; absent parents; employment; logistic regression; Survey of Activities of Young People; odds ratios

\section{Introduction}

The South African population, like elsewhere on the continent, is confronted with issues of poverty, unemployment and HIV/AIDS. It is reported that South Africa has experienced weak employment growth from 20II to late 20 I2, with annual employment growing by a mere $0.6 \%$ (Statssa, 2013). Women and young children are most affected by poverty in the country. Results from the $200 \mathrm{I}$ Census show that nearly $60 \%$ of adult women had no formal schooling (Aitchison and Harley, 2006). This compromises women's ability to obtain gainful and secure employment in the country. In the absence of such employment, the health and well-being of women and their children are at risk. Malnourishment is a disease commonly associated with poverty; $6.7 \%$ of South African female children and $7 \%$ of male children suffer this outcome (Redelinghuys and Van Rensburg, 2004).

Unemployment is another issue aggravating poverty in the country. According to Stats SA (2013) the unemployment rate in late 2012 was $24.9 \%$. Further, Stats SA notes fewer employed persons in the fourth quarter of 2012 compared to the third quarter (Statssa, 2013). The organisation has attributed this decline in number of employed persons (aged 15-49) to job losses experienced in the formal sector (down by 52,000 ) and private households (down by
$8,000)$. In an attempt to understand unemployment in South Africa, Burger and von Fintel (2009) have argued that post-Apartheid policies have contributed to factions of the population not meeting skills requirements for gainful employment. According to the authors, students "that were too old for their grade were removed from the mainstream public education system, with the intention of transition into adult education alternatives" (Burger and von Fintel, 2009). Consequently, many young South Africans were pushed into the labour market without having completed their education and without any skills (Burger and von Fintel, 2009).

The issue of education is pertinent to the continent. The education of adolescents is particularly important as it is an indicator of future employment and development. In Africa the education and employment of adolescents is key to the continent's future economic development. However, adolescents in Africa face growing limitations with regard to their education and potential employment opportunities. These challenges have been the focus of various international organisations and research. In 2003 it was noted that almost $40 \%$ of under-18s in sub-Saharan Africa were not in school (WorldBank, 2003).

Quality education is key to the development of adolescents as it equips them with the necessary

I. Corresponding author telephone number: +27722394660 
skills and knowledge to make good choices with regard to their health and financial futures. There are, however, many challenges adolescents face in obtaining quality education. For many adolescents factors such as teen pregnancy, irregular attendance, absent teachers and school related violence and abuse prevent them from obtaining any education. In South Africa, high levels of poverty have impacted on the actual premises, with $78 \%$ of public schools not having libraries and computer facilities and $27 \%$ not having running water (UNICEF, 20II). Under such circumstances quality education cannot be achieved. In addition, when African children reach adolescence they are expected to assist with household chores, caring for younger siblings and ill parents and generating income (Lowicki, 2000).

Related to this are the causes and impacts of parent absenteeism on adolescent development and well-being. In South Africa, the historically common practice of labour migration has contributed to parents, especially fathers, being absent from the household. Apartheid policies prohibiting the free movement of the non-White population meant families of which women and children were not able to move to mining areas to be close to their husbands and fathers. In more recent times, circular labour migration (Collinson et al., 2003), divorce and separation, and the more common practice of children living with grandparents have all contributed to parent absenteeism. According to Schatz (2007), grandmothers care for grandchildren whose adult parents have left them due to migration, mortality, re-marriage and unemployment. In addition, these elderly women face financial, physical and emotional strain by having to provide for their grandchildren in their own old ages (Schatz, 2007). The impact of absent parents has been well noted in literature. It is found that adolescents who experience parent absenteeism are more prone to school suspension and likely to engage in drug and alcohol abuse (Stanton et al., 2004). In more developed countries, it has been noted that teenage girls raised in the absence of fathers are more likely to suffer from depression and drop out of school. They are also more likely to fall pregnant at young ages (Nowak, 2003).

Given the extent of poverty and unemployment, as well as the challenges of obtaining education and parent absenteeism, it is understandable that adolescents will engage in paid work. The legal age of employment in South Africa is 15 years old. However, international recommendations have suggested that adolescents as young as 12 years old may engage in so-called 'light work' which is work that does not harm the person's health and development and does not interfere with their school attendance (ILO, 1973). This recommendation was made in accordance with the challenges of poverty faced by many youth in developing countries and so as to avoid exploitative child labour practices.

However, in South Africa, little is known of the employment or work practices of adolescents. This paper considers two important facets of adolescent work in the country. First, the paper considers the working levels of adolescents who have at least one or both parents absent from the household. Given the forementioned discussion, it is here assumed that most adolescents with absent parents are engaging in paid work. Second, this paper considers the hours per week spent on work. In line with the ILO recommendation, it is suggested that adolescents who work 10 hours or more a week are compromising their educational development.

\section{Data and methods}

This study uses data from the Survey of Activities of Young People (SAYP) in 2010 as compiled by Stats SA. This is the second SAYP conducted by Statistics South Africa. The idea of surveying the activities of young people is meant to supplement the data provided by the Quarterly Labour Force Survey (QLFS), which documents the activities of South African adults (Statssa, 20l Ib). The SAYP is a householdbased sample survey that collects data on the activities of South African adolescents aged between 7 and 17 years old.

The survey has been conducted in households that were selected for the third quarter QLFS for 2010, and who have resident adolescent household members. The QLFS frame has been developed as a general-purpose household survey frame that can be used by all other household surveys even if the sample size requirements differ. The sample is based on information collected during the 200I Population Census also conducted by Stats SA. The sample size for the third QLFS for 2010 was 3,080 primary sampling units. These were equally divided into four subgroups called rotation groups. The rotation groups, each with the same distribution pattern, are numbered to correspond with the quarter of the year in which the sample is rotated for each sub-group (first, second, third and fourth quarter). Using a twostage sampling design (sampling of proportional to size primary sampling units and then sampling dwelling units), one quarter of the sampled dwellings rotate out of the sample for each quarter. In doing so sampled dwellings remain in the sample for four consecutive quarters (Statssa, 20lla). The number of households that participated in the SAYP in 2010 was 17,372.

Despite the sampling procedure being linked to the QLFS, Stats SA caution against merging the SAYP 
and QLFS data: "some children who were identified during QLFS did not respond during the follow-up interviews. Users are therefore advised to compare QLFS Q3:2010 estimates with SAYP estimates with caution" (Statssa, 20 I lb).

The survey covers market production activities, production for own final consumption, household chores and activities conducted at school. The SAYP collects data on the demographic and socio-economic characteristics of adolescents, including among others, gender, population group/race, province of residence, level of education, number of hours worked and occupation. The survey also collects information on whether the adolescent's mother and/or father are members of their household. It is from these latter questions that parentabsenteeism is derived. If either the mother or father are not members of the household, it is classified as 'at least one parent absent'. If both mother and father are not members of the household, it is classified as 'both parents absent'.

The main outcome being analysed in this paper is whether or not adolescents ( $10-17$ years old) are engaging in paid work for 10 or more hours a week. The condition of number of hours worked a week is included as international law allows for adolescents as young as 12 years old to engage in 'light' labour (ILO, 1973). This implies a few hours of non-threatening and non-strenuous work a week. When engaging in labour of any kind for longer than 10 hours a week, an adolescent's education becomes compromised. The number of adolescents in South Africa who work 10 hours or more a week is 1.58 adolescents per 1,000 adolescent population.

This study produces descriptive statistics, showing the distribution of adolescents who work by demographic characteristics. Special attention is paid to whether there is at least one parent (either mother of father) not residing in the household or both parents are absent from the residence. Multivariate analysis is used to identify if any associations exist between adolescents working 10 hours or more a week and various demographic characteristics (sex, population group, province of residence), as well as parent absenteeism. Logistic regression is used because the outcome is binary (worked 10 or more hours last week - yes/no).

\section{Results}

Distribution of adolescent participation in the labour force in South Africa

Table I Number and percentage distribution of adolescents who work less than or 9 hours a week and more than or 10 hours a week, South Africa, 2010

\begin{tabular}{|c|c|c|c|c|c|c|}
\hline \multirow[t]{3}{*}{ Demographic variables } & \multicolumn{6}{|c|}{ Number of Hours Worked a Week } \\
\hline & \multicolumn{2}{|c|}{ Less than or 9 hours } & \multicolumn{2}{|c|}{ More than or 10 hours } & \multicolumn{2}{|l|}{ Total } \\
\hline & $\overline{\mathbf{n}}$ & $\%$ & n & $\%$ & n & $\%$ \\
\hline Total & 17,846 & 100 & 9,666 & 100 & 27,512 & 100 \\
\hline \multicolumn{7}{|l|}{ Sex } \\
\hline Male & 13,225 & 74.11 & 6,242 & 64.58 & 19,467 & 70.76 \\
\hline Female & 4,621 & 25.89 & 3,424 & 35.42 & 8,044 & 29.24 \\
\hline \multicolumn{7}{|l|}{ Population Group } \\
\hline African/ Black & 12,962 & 72.64 & 7,351 & 76.05 & 20,314 & 73.84 \\
\hline Coloured & 2,595 & 14.54 & 1,780 & $|8.4|$ & 4,375 & 15.90 \\
\hline Indian/ Asian & $\mathrm{I}, 377$ & 7.72 & 0 & 0.00 & I,377 & 5.01 \\
\hline White & 911 & 5.11 & 535 & 5.53 & 1,446 & 5.26 \\
\hline \multicolumn{7}{|l|}{ Province } \\
\hline Western Cape & 644 & 3.61 & 1,595 & 16.50 & 2,239 & 8.14 \\
\hline Eastern Cape & 4,666 & 26.15 & 1,566 & 16.20 & 6,232 & 22.65 \\
\hline Northern Cape & $\mathrm{I}, 042$ & 5.84 & 185 & 1.91 & 1,227 & 4.46 \\
\hline Free State & 504 & 2.83 & 0 & 0.00 & 504 & 1.83 \\
\hline KwaZulu-Natal & 8,138 & 45.61 & 1,693 & $|7.5|$ & 9,831 & 35.73 \\
\hline North West & 887 & 4.97 & 2,210 & 22.86 & 3,096 & 11.25 \\
\hline Gauteng & 0 & 0.00 & 535 & 5.53 & 535 & 1.94 \\
\hline
\end{tabular}




\begin{tabular}{lll|ll|ll} 
Mpumalanga & 256 & 1.44 & 840 & 8.69 & 1,096 & 3.98 \\
Limpopo & 1,708 & 9.57 & 1,043 & 10.79 & 2,750 & 10.00 \\
\hline Currently attending school & & & & & & \\
Yes & 15,810 & 88.59 & 5,516 & 57.07 & 21,326 & 77.52 \\
No & 2,036 & 11.41 & 4,150 & 42.93 & 6,186 & 22.48 \\
\hline
\end{tabular}

Table I shows the number and percentage distribution of adolescents who engage in paid work in South Africa. The table shows the distribution of adolescents who work 9 hours or less and those who work 10 hours or more. The latter group are of interest to this study. The table shows that $64.58 \%$ of adolescents who work 10 hours or more are male, compared to the $35.42 \%$ who are female.

By population group, the table shows that $76.05 \%$ of adolescents who work 10 hours or more are Black/African. For the Indian/Asian population, approximately $9 \%$ of adolescents reportedly worked 9 hours or less a week, however none reported working 10 hours or more. The percentage distribution for White adolescents working 10 hours or more is lowest at $5.53 \%$.

According to province, KwaZulu-Natal has the highest number of adolescents who work 9 hours or less a week (45.61\%) and the second highest number of adolescents who work 10 hours or more (17.51\%). The North-West province has the highest number of adolescents who work 10 hours or more a week at $22.86 \%$. In total, however, KwaZuluNatal have the highest number of adolescents who work (in both categories) at $35.37 \%$ of all working adolescents in the country.

Finally, the table shows that $88.59 \%$ of adolescents who work 9 hours or less a week are currently enrolled in school. This percentage drops to $57.07 \%$ of adolescents who work 10 hours or more a week being enrolled in school.

Distribution of adolescents by parent absenteeism, South Africa

Table 2 Number and percentage distribution of adolescents with at least one parent or both parents absent, South Africa, 2010

\begin{tabular}{|c|c|c|c|c|}
\hline \multirow[t]{2}{*}{ Demographic variables } & \multicolumn{2}{|c|}{ At least I parent absent } & \multicolumn{2}{|c|}{ Both parents absent } \\
\hline & $\mathbf{n}$ & $\%$ & n & $\%$ \\
\hline Predictor Variables & $2,362,840$ & 100 & $1,005,135$ & 100 \\
\hline \multicolumn{5}{|l|}{ Sex } \\
\hline Male & $1,182,419$ & 50.04 & 508,574 & 50.6 \\
\hline Female & $|| 80,,42 \mid$ & 49.96 & 496,561 & 49.4 \\
\hline \multicolumn{5}{|l|}{ Population Group } \\
\hline African/ Black & $2,117,949$ & 89.64 & 947,732 & 94.29 \\
\hline Coloured & $|57,56|$ & 6.67 & 40,981 & 4.08 \\
\hline Indian/ Asian & 14,537 & 0.62 & 4,303 & 0.43 \\
\hline White & 72,793 & 3.08 & 12,119 & 1.21 \\
\hline \multicolumn{5}{|l|}{ Province } \\
\hline Western Cape & 180,966 & 7.66 & $58,|2|$ & 5.78 \\
\hline Eastern Cape & 355,252 & 15.03 & 198,259 & 19.72 \\
\hline Northern Cape & 60,427 & 2.56 & 16,842 & 1.68 \\
\hline Free State & 98,586 & 4.17 & 45,221 & 4.5 \\
\hline KwaZulu-Natal & 576,579 & 24.4 & 208,256 & 20.72 \\
\hline North West & 167,927 & 7.11 & 77,904 & 7.75 \\
\hline Gauteng & 371,768 & 15.73 & 98,381 & 9.79 \\
\hline Mpumalanga & 229,690 & 9.72 & 103,921 & 10.34 \\
\hline Limpopo & 321,645 & 13.61 & 198,230 & 19.72 \\
\hline \multicolumn{5}{|c|}{ Currently attending school } \\
\hline Yes & $2,318,905$ & 98.14 & 973,342 & 96.84 \\
\hline No & 43,935 & 1.86 & 31,793 & 3.16 \\
\hline
\end{tabular}

Note: Total number of adolescents is 6,105,600 
Table 2 shows the percentage distribution of adolescents with at least one or both parents absent from the household by individual characteristics in 2010 . The table shows that slightly more adolescent males are living without both parents $(50.6 \%)$ than without at least one parent $(50.1 \%)$. For adolescent females, the opposite is true, with slightly more females living without one parent $(49.96 \%)$ than without both parents (49.4\%).

The distribution of adolescents with at least one parent or both parents absent by population group shows that the majority of adolescents living without one or both parents are Black/African adolescents. In addition, more Black/African adolescents live without both parents (94.29\%) than without at least one parent $(89.64 \%)$. The number of Coloured adolescents living without one parent is higher at $6.67 \%$ compared to the $4.08 \%$ living without both parents.

The percentage distribution of adolescents with at least one or both parents absent by province of residence shows that KwaZulu Natal has the highest percent of adolescents with at least one parent absent at $24.4 \%$. The province with the lowest percentage of adolescents with at least one parent absent is the Northern Cape at $2.56 \%$. For adolescents with both parents being absent from the household, again KwaZulu Natal has the highest percent at $19.72 \%$. The table also shows that in the Western Cape, Northern Cape, KwaZulu Natal and Gauteng, there are more adolescents living without at least one parent than without both parents.

From Table 2 it is seen that about $98 \%$ of adolescents who have at least one parent absent are still attending school. This percentage drops to $96 \%$ when both parents are absent from the household. Further almost $2 \%$ of adolescents with at least one parent absent are not enrolled in school in South Africa. For adolescents who have both parents absent from the household, $3.16 \%$ are not enrolled in school.

Distribution of adolescents who work 10 hours or more a week by parent absenteeism, South Africa

\begin{tabular}{|c|c|c|c|c|}
\hline \multirow[t]{2}{*}{ Demographic variables } & \multicolumn{2}{|c|}{ At least I parent absent } & \multicolumn{2}{|c|}{ Both parents absent } \\
\hline & $\overline{\mathbf{n}}$ & $\%$ & n & $\%$ \\
\hline Total & 5,553 & 57.45* & 638 & 6.6** \\
\hline \multicolumn{5}{|l|}{ Sex } \\
\hline Male & 3,092 & 55.69 & 638 & 100 \\
\hline Female & 2,460 & 44.31 & & \\
\hline \multicolumn{5}{|l|}{ Population Group } \\
\hline African/ Black & 5,018 & 90.37 & 638 & 100 \\
\hline White & 535 & 9.63 & & \\
\hline \multicolumn{5}{|l|}{ Province } \\
\hline Eastern Cape & 928 & 16.71 & 638 & 100 \\
\hline KwaZulu-Natal & 954 & 17.18 & & \\
\hline North West & 1,639 & 29.52 & & \\
\hline Gauteng & 535 & 9.63 & & \\
\hline Mpumalanga & 840 & 15.13 & & \\
\hline Limpopo & 657 & 11.84 & & \\
\hline \multicolumn{5}{|c|}{ Currently attending school } \\
\hline Yes & $3,8 \mid 4$ & 68.68 & 638 & 100.00 \\
\hline No & 1,739 & 31.32 & & \\
\hline
\end{tabular}

*This is the proportion of adolescents with at least one parent absent from the household who work 10 or more hours a week, out of all adolescents who worked 10 hours or more.

** This is the proportion of adolescents with both parents absent from the household who work 10 or more hours a week, out of all adolescents who worked 10 hours or more.

Table 3 shows that $57.45 \%$ of all adolescents who worked 10 hours or more a week have at least one parent absent from the household. The table shows that more males $(55.69 \%)$ than females $(44.31 \%)$ with at least one parent absent worked. Further, no Coloured or Indian/Asian adolescents without at least one or both parents worked. By province of residence almost $30 \%$ of adolescents in the North 
West and $17.18 \%$ from KwaZulu Natal in the absence of one parent from the household worked 10 or more hours a week. Finally $31.32 \%$ of adolescents who worked in the absence of at least one parent at home, were not enrolled in school.

Table 3 also shows that $6.6 \%$ of adolescents with both parents absent from the household engaged in 10 hours or more of paid work in the week prior to the interview. The table shows that only males reported having worked 10 hours or more and no Coloured, Indian/Asian or White adolescents without both parents worked. By province, only adolescents in the Eastern Cape reported engaging in paid work for 10 or more hours a week. Finally, all adolescents (638) who worked in the absence of both parents, reported being enrolled in school.

\section{Multivariate logistic regression}

Model I is the multivariate logistic regression including whether or not the adolescent's mother is a member of the household. Model II includes whether the adolescent's father is a member of the household and the final model (Model III) shows the odds of adolescents engaging in paid work for 10 or more hours a week with both parents not being members of the household. Statistically significant
( $\mathrm{p}$-values <0.05) are here discussed.

To begin, Model I shows that if the adolescent's mother is not a member of the household (0.34) and female (0.39) there are lesser odds the adolescent working 10 or more hours a week. However, if the adolescent is Coloured (1.79) or White (1.42) and not enrolled in school (32.92) there is a greater chance that they are working 10 hours or more a week.

In Model II, it is seen that if the father is absent from the household there are greater odds of the adolescent working 10 hours or more a week with odds of I.2I. Further, in the absence of a father, adolescent females (0.33) from the Eastern Cape (0.8I), Gauteng (0.85) or Limpopo (0.92) are less likely to work. However, Black/African adolescents (I.95) who are not enrolled in school (33.08) are more likely to be working more than 10 hours a week, in the absence of a father in the household.

Finally, for Model III, both parents being absent from the household, population group and province of residence is not statistically significant. However, the model shows that females $(0.35)$ have less odds of working 10 hours or more a week and again, adolescents that are not enrolled in school (32.52) are more likely to be working.

Table 4 Multivariate logistic regression producing odds ratios, showing the likelihood of adolescents working more than 10 hours a week by mother, father or both parents not being household members, South Africa, 2010

\begin{tabular}{|c|c|c|c|c|c|c|}
\hline \multirow[t]{2}{*}{ Characteristics } & \multicolumn{2}{|l|}{ Model I } & \multicolumn{2}{|l|}{ Model II } & \multicolumn{2}{|l|}{ Model III } \\
\hline & Odds Ratio & P-value & Odds Ratio & P-value & Odds Ratio & P-value \\
\hline \multicolumn{7}{|c|}{ Mother member of household } \\
\hline Yes & $\mathrm{RC}$ & & - & & - & \\
\hline No & 0.34 & 0.016 & - & & - & \\
\hline \multicolumn{7}{|c|}{ Father member of household } \\
\hline Yes & - & & $\mathrm{RC}$ & & - & \\
\hline No & - & & 1.21 & 0.037 & - & \\
\hline \multicolumn{7}{|c|}{ Both parents absent from household } \\
\hline Yes & - & & - & & $\mathrm{RC}$ & \\
\hline No & - & & - & & 0.43 & 0.268 \\
\hline \multicolumn{7}{|l|}{ Gender } \\
\hline Male & $\mathrm{RC}$ & & $\mathrm{RC}$ & & $\mathrm{RC}$ & \\
\hline Female & 0.39 & 0.028 & 0.33 & 0.025 & 0.35 & 0.03 \\
\hline \multicolumn{7}{|c|}{ Population Group } \\
\hline African/ Black & $\mathrm{RC}$ & & $\mathrm{RC}$ & & $\mathrm{RC}$ & \\
\hline Coloured & 1.79 & 0.042 & 1.95 & 0.041 & $\mathrm{I} .75$ & 0.54 \\
\hline Indian/Asian & (omitted) & & (omitted) & & (omitted) & \\
\hline White & 1.42 & 0.042 & 1.50 & 0.051 & 1.26 & 0.831 \\
\hline \multicolumn{7}{|c|}{ Currently attending school } \\
\hline Yes & $\mathrm{RC}$ & & $\mathrm{RC}$ & & $\mathrm{RC}$ & \\
\hline No & 32.92 & 0.000 & 33.08 & 0.000 & 32.52 & 0.000 \\
\hline
\end{tabular}

\section{Province}




\begin{tabular}{lllllll} 
Western Cape & RC & & RC & & RC \\
Eastern Cape & 0.89 & 0.002 & 0.81 & 0.052 & 0.86 & 0.891 \\
Northern Cape & 1.07 & 0.056 & 1.09 & 0.042 & 1.08 & 0.946 \\
Free State & 1.03 & 0.085 & 1.01 & 0.095 & 0.97 & 0.98 \\
KwaZulu-Natal & 1.13 & 0.011 & 1.06 & 0.058 & 1.10 & 0.929 \\
North West & 4.59 & 0.014 & 4.30 & 0.059 & 4.38 & 0.152 \\
Gauteng & 0.83 & 0.087 & 0.85 & 0.006 & 0.82 & 0.883 \\
Mpumalanga & 2.44 & 0.028 & 2.30 & 0.062 & 2.38 & 0.443 \\
Limpopo & 0.98 & 0.089 & 0.92 & 0.042 & 0.96 & 0.971 \\
\hline
\end{tabular}

\section{Discussion and conclusion}

This study has shown that adolescents living in the provinces of KwaZulu Natal and the Eastern Cape experience the most parent absenteeism. It has been acknowledged in prior research that orphans in the KwaZulu Natal (27\%) and Eastern Cape (30\%) provinces combined account for approximately half of all orphans in the country (Meintjies and Hall, 20II). The unemployment of adults may be a factor contributing to parent absenteeism and orphanhood in these provinces. According to the fourth QLFS of 2010, KwaZulu Natal was among the hardest hit provinces with regard to job losses. This province accounted for $31.36 \%$ of national job losses in 2010 alone (Statssa, 20I la). For the Eastern Cape province, adult unemployment decreased by $10.97 \%$ from 2005 to 2010 (ECSECC, 20I2). During the same period, national figures show that employment among adults increased by $13.72 \%$. Due to these worrying provincial trends, adults in these provinces probably moved to other areas in search of employment opportunities leaving behind children and adolescents. And with parents being mostly absent, it is understandable that adolescents would engage in 10 hours or more of work in these regions, which is what this study has found.

Adolescent males more commonly have both parents absent from the household, while adolescent females are predominantly living in one parent households. Of all the population groups, Black/African adolescents are more affected by parent absenteeism than any other race in South Africa. Johnson and Dorrington (200I) found that the proportion of South African orphans who are Black/African is higher than the proportion of orphans in any other population group. The authors attribute this to the larger number of AIDS deaths among the Black/African population as well as higher levels of fertility among this group in the country (Johnson and Dorrington, 200I). Employment inequalities and labour migration patterns of the Black/African population could also explain the large numbers of adolescents experiencing parent absenteeism. In the fourth quarter of 2010 , the unemployment rate among Black/
Africans was $28.1 \%$ (Statssa, 20I la). In addition, Posel et al. (2003) found that labour migration patterns among Black/ Africans in South Africa is still an important feature of the South African labour market. According to the authors labour migration from Black/African rural households in the country have increased since 1994 (Posel and Casale, 2003).

An association was found between parent absenteeism and working more than 10 hours a week. Adolescents are less likely to work more than 10 hours or more a week if a mother is absent from the household $(0.34)$, yet more likely to work as many hours if a father is absent from the home (I.2I). This could be attributed to gendered income inequalities in South Africa which shows the extent and depth of poverty was significantly higher for females and for female-headed households over the period 19972006 (Posel and Rogan, 2010). Given this situation, should a father be unemployed or absent, financial constraints in a household would be more menacing than if a mother is unemployed or absent. Therefore, given the lower income of mothers and the absenteeism of fathers in the household, adolescents would be expected to enter the labour force early.

Approximately $4 \%$ of South African adolescents, with one or both parents absent, are not enrolled in school. In addition, adolescents who experience parent absenteeism are more likely to be working 10 hours or more a week if they not enrolled in school. This finding is similar to results found on orphans in the region. A study on the school enrolment of orphans in sub-Saharan African countries, found that orphans are less likely to attend school than nonorphans on the continent (Case et al., 2003). Anderson (2003) found that children who live with neither parent are the least likely to be enrolled in school, and have completed the fewest grades per year. In addition, children who live with their father but not their mother are $61 \%$ as likely to be enrolled as children living with both parents. According to Anderson, these results suggest a reduced investment in children's education when both parents are not present. His reasons for this "include increasingly complex household bargaining dynamics as well as 
parental tradeoffs over the allocation of resources to children versus other ends" (Anderson, 2003).

Literature has found that single-income households are poorer than dual income households in South Africa (Barrett et al., 2005, Smit, 1998, Simkins, 2004). In the absence of a parent (or both) adolescents would join the labour force before completing school to combat household poverty. The adolescent may do so out of choice, to supplement the household budget and perhaps gain some financial independence. Or the adolescent may be forced to seek employment to assist with the increased costs of large household sizes.

Adult mortality is another reason adolescents seek work. In a study on the effect of prime-age adult mortality due to HIV/AIDS in South Africa, it was found that "adolescents exit school in order to compensate for a possible loss or reduction of household income, to smooth consumption or to look after the household and its members" (Yamauchi et al., 2008). This study found that females enter the labour force in the period immediately before the death of an adult household member, while adolescent males seek employment after a death has occurred (Yamauchi et al., 2008). Given this, it appears to be practice to forego the education of adolescent females before males in the population. This could mean that females will be younger than males when they enter the labour force and less educated since they are taken out of school even before a household death occurs.

These findings are particularly relevant to youth and social development policies in South Africa. The results of this study show a shift in family structure, whereby adolescents are not living in the same households as one or both of their parents. This paper has examined a consequence of such living arrangements and found that parent absenteeism causes adolescents to participate in the labour force for 10 hours or more a week. However, parent absenteeism also alludes to the corroding stability of families in South Africa. Households and families in the country face the growing challenges of poverty, crime and HIV/AIDS. The family unit is seen as the first response to countering such challenges through the division and sharing of income and resources. So when the family structure changes and parents and care-givers are absent from the unit, the challenges are left to grandparents, children and adolescents to bear.

With parents being absent from households, adolescents are forced to take up employment. Although this is not illegal for those aged 15 and above, if adolescents are working more than 10 hours a week, their school completion is jeopardised. The long-run implication of this is that South
African adolescents will become unskilled adult labourers who struggle to find employment. South Africa is in a unique position to invest in its large adolescent and youth population now, so as to reap the economic and development rewards later on. If adolescents are not encouraged to work, but rather to complete their education, the country will breed a labour force of skilled and able-bodied adults in the future.

\section{References}

Aitchison, J. \& Harley, A. 2006. "South African illiteracy statistics and the case of the magically growing number of literacy and ABET learners". Journal of Education, 39.

Anderson, K. 2003. "Family Structure, Schooling Outcomes, and Investment in Education in South Africa". In: Population Studies Center At The Institute For Social Research, U. O. M. (ed.) PSC Research Report, No. 03-538.

Barrett, C. B., Clark, M. B., Clay, D. C. \& Reardon, T. 2005. "Heterogeneous constraints, incentives and income diversification strategies in rural Africa". Quarterly journal of international agriculture, 44 , 37-60.

Burger, R. \& Von Fintel, D. 2009. "Determining the Causes of the Rising South African Unemployment Rate: An Age, Period and Generational Analysis". Working Papers 24/2009. Stellenbosch University, Department of Economics.

Case, A., Paxson, C. \& Ableidinger, J. 2003. "The Education of African Orphans". Princeton University.

Collinson, M., Tollman, S., Kahn, K. \& Clark, S. 2003. "Highly prevalent circular migration: Households, mobility and economic status in rural South Africa".

ECSECC 2012. "Youth Employment and Unemployment". In: Eastern Cape Socio Economic Consultative Council (ed.) Economic Update.

ILO 1973. "Minimum Age for Admission to Employment". Report number CI38 of ILO.

Johnson, L. \& Dorrington, R. 200I. "The Impact of AIDS on Orphanhood in South Africa: a Quantitative Analysis". CARE Monograph, 4.

Lowicki, J. 2000. "Untapped potential: adolescents affected by armed conflict. A review of programs and policies", New York, Women's Commission for Refugee Women and Children.

Meintjies, H. \& Hall, K. 20I I. "Demography of South Africa's children". In: Jamieson, L., Bray, R., Viviers, A., Lake, L., Pendlebury, S. \& Smith, C. (eds.) South African Child Gauge 2010/ 2011. Children's Institute University of Cape Town. 
Nowak, R. 2003. "Absent Fathers Linked to Teenage Pregnancies". NewsScientist.

Posel, D. \& Casale, D. 2003. "What Has Been Happening To Internal Labour Migration In South Africa, 1993-1999?" South African Journal of Economics, 7I, 455-479.

Posel, D. \& Rogan, M. 2010. "Gendered trends in income poverty in post-apartheid South Africa, 1997- 2006". In: Ten years of 'war against poverty': what have we learned since 2000 and what should we do 2010- 2020? . University of Manchester.

Redelinghuys, N. \& Van Rensburg, H. 2004. "Health, Morbidity and Mortality: The health

status of the South African population". In: Van Rensburg, H. (ed.) Health and Healthcare in South Africa. Pretoria: Van Schaik.

Schatz, E. J. 2007. "Taking care of my own blood": Older women's relationships to their households in rural South Africa". Scandinavian Journal of Public Health, 35, I47-I 54.

Simkins, C. 2004. "What happened to the distribution of income in South Africa between 1995 and 200I". University of the Witwatersrand.

Smit, W. 1998. "The rural linkages of urban households in Durban, South Africa". Environment and Urbanization, 10, 77-88.
Stanton, B., Cole, M., Galbraith, J., Li, X., Pendleton, S., Cottrel, L., Marshall, S., Wu, Y. \& Kaljee, L. 2004. "Randomized trial of a parent intervention: parents can make a difference in long-term adolescent risk behaviors, perceptions, and knowledge". Archives of pediatrics \& adolescent medicine, I58, 947.

STATSSA 20I I a. "Quarterly Labour Force Survey: Quarter 4, 2010". Pretoria, South Africa: Stats SA.

STATSSA 20l I b. "Survey of Activities of Young People, 2010". Pretoria: Statistics South Africa.

STATSSA 2013. "Quarterly Labour Force Survey, Quarter 4, 2012". Pretoria: Statistics South Africa.

UNICEF 20II. "Overview: Education and adolescent development". In: UNICEF (ed.) Education and Child Friendly Schools.

Worldbank. 2003. "Adolescent Health and Development in Africa" [Online]. Available: http://web.worldbank.org/.

Yamauchi, F., Buthelezi, T. \& Velia, M. 2008. "Impacts of Prime-age Adult Mortality on Labour Supply: Evidence from Adolescents and Women in South Africa". Oxford Bulletin of Economics and Statistics, 70, 375-398. 